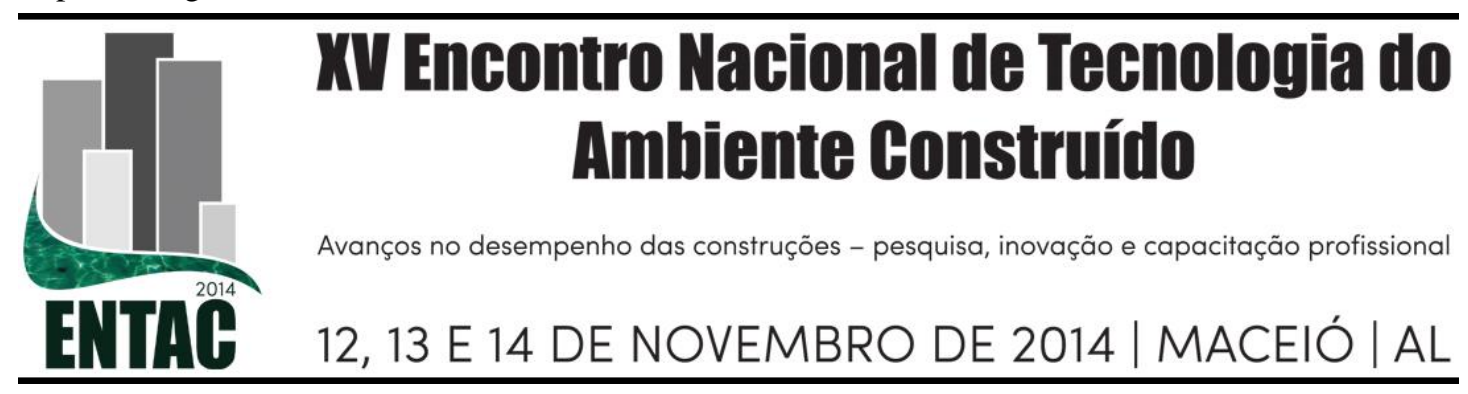

\title{
QUALIDADE AMBIENTAL E SUSTENTABILIDADE EM EDIFICÍCIOS DE APARTAMENTOS DE CIDADES MÉDIAS
}

\author{
SARAMAgo, Rita de Cássia Pereira (1); VILLA, Simone Barbosa (2); BEZZON, \\ Eduardo Franklin Almeida (3); ARANTES, Larissa Carvalho (4) \\ (1) Universidade Federal de Uberlândia, e-mail: saramagorita@gmail.com (2) Universidade Federal de \\ Uberlândia, e-mail: simonevilla@yahoo.com (3) Universidade Federal de Uberlândia, e-mail: \\ eduardobezzon@gmail.com (4) Universidade Federal de Uberlândia, e-mail: larissac.arantes@ gmail.com
}

\begin{abstract}
RESUMO
A presente comunicação objetiva apresentar resultados parciais de uma pesquisa mais ampla, intitulada "HABITAR VERTICAL: Avaliação da qualidade espacial e ambiental de edifícios de apartamentos", cujo intuito é realizar um diagnóstico da qualidade das habitações coletivas verticais, destinadas à classe média e lançadas pelo mercado imobiliário em cidades de médio porte brasileiras (Uberlândia - MG e Ribeirão Preto - SP). Nesse contexto, este trabalho, que enfoca a qualidade ambiental das edificações, foi estruturado da seguinte maneira: (i) contextualização da problemática e apresentação dos objetivos da pesquisa; (ii) fundamentação teórica do trabalho, através de revisão bibliográfica; (iii) indicação da metodologia utilizada na investigação; e (iv) descrição do desenvolvimento da pesquisa. Tal descrição contempla as duas etapas iniciais realizadas: (a) mapeamento das estratégias de sustentabilidade colocadas em prática nos empreendimentos residenciais brasileiros, por meio da elaboração de fichas de análise sobre os mesmos; (b) revisão e ampliação do método de Avaliação Pós-Ocupação (APO) desenvolvido em pesquisas anteriores para englobar questões relativas à qualidade ambiental e à sustentabilidade dos edifícios analisados. Os resultados parciais apontam para a baixa incorporação de estratégias de sustentabilidade e para a precária qualidade ambiental dos edifícios verticais investigados. A etapa seguinte pretende aplicar o método de APO desenvolvido, verificando a eficiência das estratégias de sustentabilidade adotadas junto aos usuários, bem como seu nível de consciência ambiental.
\end{abstract}

Palavras-chave: Qualidade ambiental, Estratégias de sustentabilidade, Avaliação Pós-Ocupação, Edifícios de apartamentos, Cidades de médio porte.

\begin{abstract}
This communication aims to present partial results of a larger study entitled "VERTICAL HOUSING: Evaluation of spatial and environmental quality of apartment buildings", which aims to diagnoses the quality of vertical housing, designed for middle-class and launched by the housing market in Brazilian mid-sized cities (Uberlândia - MG, Ribeirão Preto - SP). In this context, this paper, which focuses on the environmental quality of the buildings, was structured as follows: (i) contextualization of the problem and presentation of the general objectives of the research; (ii) description of theoretical basis of the work, through literature review; (iii) indication of the methodology used in research; (iv) description of its development. This description includes two steps concluded: (a) mapping of sustainability strategies put into practice in the Brazilian residential developments through analysis' schemes of them; (iii) review and expansion of the post-occupancy evaluation (POE) method initially developed in other researches in order to encompass the aspects of environmental quality and sustainability of the buildings analyzed. The partial results point to the low incorporation of sustainability strategies and to the poor environmental quality of vertical buildings in the cities analyzed. The next stage of the research consists of applying the POE method developed, aiming to verify the effectiveness of sustainability strategies adopted in the buildings, as well as the level of environmental awareness of their users.
\end{abstract}

Keywords: Environmental quality, Sustainability strategies, Post-Occupancy Evaluation, Apartment buildings, Mid-sized cities. 


\section{INTRODUÇÃO}

O crescimento da produção de edifícios de apartamentos, especialmente voltado à ascendente classe média da sociedade, vem demonstrando, em geral, pouca preocupação com a qualidade das unidades e dos empreendimentos ofertados. Sendo assim, a pesquisa HABITAR VERTICAL - Avaliação da qualidade espacial e ambiental de edifícios de apartamentos tem como objetivo principal realizar um diagnóstico da qualidade das habitações verticais destinadas à classe média e lançadas pelo mercado imobiliário em cidades de médio porte brasileiras (Uberlândia - MG e Ribeirão Preto SP). Tal análise será fundamentada, principalmente, por meio da aplicação de avaliação pós-ocupação (APO) em relação aos aspectos de funcionalidade, conforto ambiental e sustentabilidade presentes nos edifícios investigados. Assim, por se tratar de um projeto de pesquisa amplo, que envolve várias etapas de execução, este foi dividido em duas linhas de investigação, que enfocam: (a) funcionalidade e (b) qualidade ambiental e sustentabilidade. Nesse contexto, esta comunicação apresenta os objetivos, métodos e resultados parciais referentes à segunda linha de investigação, que se propõe a:

- Mapear as estratégias de sustentabilidade concebidas durante o planejamento e operacionalizadas na fase de construção dos empreendimentos residenciais das cidades estudadas;

- Testar e validar os métodos de APO desenvolvidos em pesquisas anteriores (VILLA, 2008; VILLA, 2010), ampliando-os no sentido de contemplar a inserção de itens avaliativos sobre a sustentabilidade e a qualidade ambiental das edificações;

- Criar um quadro comparativo da produção imobiliária nas cidades estudadas, por meio da tabulação dos resultados obtidos nas aplicações da APO, contribuindo para a melhoria da qualidade dos edifícios de apartamentos ofertados.

Os dois primeiros objetivos da pesquisa geral foram concluídos, sendo que seus resultados são apresentados nesta comunicação. Já a elaboração do quadro comparativo depende da aplicação de APO nos estudos de caso - etapa ainda em desenvolvimento. Considera-se, portanto, a hipótese de que a qualidade projetual tende a melhorar através da montagem e observação, por parte dos arquitetos, agentes imobiliários públicos e privados, de bancos de dados municiados por avaliações pós-ocupação. A pesquisa também pretende identificar a presença de estratégias sustentáveis nos empreendimentos estudados. $\mathrm{O}$ intuito de tal abordagem é tanto traçar um panorama da abrangência do debate sobre desenvolvimento sustentável no setor, quanto identificar - mediante consulta aos usuários - o nível de consciência ambiental dos moradores por meio da análise de seus hábitos e ações.

\section{FUNDAMENTAÇÃO TEÓRICA}

$\mathrm{O}$ surgimento da modalidade apartamento no Brasil remonta à primeira década do século XX, quando as principais cidades passaram por importantes remodelações urbanísticas, conferindo à habitação convencional térrea novas possibilidades formais e programáticas - como é o caso dos edifícios múltiplo-uso que mesclavam habitações e escritórios. Durante a década de 1990, por sua vez, observa-se, em algumas cidades de médio porte - como Uberlândia (MG) e Ribeirão Preto (SP) -, certa diversificação do mercado imobiliário, ampliando-se as áreas de produção de edifícios de apartamentos para além dos principais centros urbanos do país. Em meados dos anos 2000, esses mercados imobiliários iniciaram um processo de atratividade de empresas de maior porte, oriundas de outras regiões brasileiras. Além disso, devido a políticas governamentais, houve um significativo aumento do acesso ao crédito nos últimos anos, conferindo maior 
elasticidade ao mercado brasileiro e impulsionando a demanda por diferentes tipologias de unidades habitacionais em todo o país (VILLA, 2008; CORDEIRO FILHO, 2008).

Contudo, o crescimento da produção de habitação coletiva vertical, notadamente voltada à ascendente classe média da sociedade, vem sendo frequentemente marcado pela adoção de aspectos padronizados em soluções projetuais diversas - o que demonstra, em geral, pouca preocupação com as reais necessidades do usuário final, cujos modos de vida e formatos familiares estão em constante alteração. Entre as várias transformações pelas quais passou a sociedade brasileira desde o surgimento da tipologia apartamento e que sugerem a consolidação de novas demandas espaciais, podem ser citadas: a inserção da mulher no mercado de trabalho, com a consequente alteração de papéis sociais; e o aparecimento de diferentes formações familiares, não tradicionais - a exemplo de pessoas vivendo sozinhas e de casais sem filhos (BRANDÃO; HEINECK, 2003).

Atualmente a discussão sobre o parque residencial consolidado e em construção também vem sendo marcada pela crescente importância adquirida pelas questões concernentes à sustentabilidade do ambiente construído. Porém, muitas vezes, a incorporação de estratégias projetuais que se dizem sustentáveis na concepção e desenvolvimento dos empreendimentos imobiliários voltados à classe média é realizada com o objetivo principal de atrair a atenção de futuros investidores e usuários - ou seja, as soluções propostas são entendidas, sobretudo, enquanto estratégias de propaganda e marketing (VASCONCELOS; VASCONCELOS, 2008).

De maneira geral, podem ser enumeradas algumas estratégias recorrentes e que aparecem como indicativos de sustentabilidade: a coordenação de projetos na fase de concepção da obra, com o intuito de reduzir a produção de resíduos em virtude da resolução prévia de eventuais interferências entre os sistemas prediais das edificações; a redução de desperdícios na execução, mediante a adoção de métodos de construção mais eficientes; o uso de aquecimento solar ou de outra fonte energética renovável; o aproveitamento da ventilação e da iluminação naturais; o reuso de água de chuva; e a adoção de equipamentos e de materiais construtivos economizadores de energia.

A adoção dessas e de outras medidas voltadas à sustentabilidade do ambiente construído deve ser entendida dentro de um contexto mais amplo de revisão dos paradigmas da sociedade ocidental, em função da eminência de um possível colapso ambiental (EDWARDS; HYETT, 2005). Especificamente no setor de construção brasileiro, segundo Lamberts et al. (1997), tal revisão iniciou-se a partir da crise de energia da década de 1970, quando o embargo do petróleo demonstrou a inadequabilidade da dependência energética do país em relação a outras nações. No caso específico dos empreendimentos imobiliários, Vasconcelos e Vasconcelos (2008) analisam que a preocupação com a sustentabilidade tem sido expressa principalmente a partir da participação das empresas em processos de certificação.

A criação de um selo de certificação adquire, desse modo, a finalidade de determinar critérios para que os consumidores possam comparar as edificações em termos mais objetivos. Ao longo do tempo, diferentes selos que indicam ações de sustentabilidade em edificações foram criados, destacando-se: o BREEAM (BRE Environmental AssessmentMethod), o LEED (Leadership in Energy and Environmental Design) e o HQE (Haute QualitéEnvironnementale), respectivamente organizados na Inglaterra, Estados Unidos e França. Existe ainda um processo de certificação eminentemente nacional, visto que a Eletrobrás e o Instituto Nacional de Metrologia, Normalização e Qualidade Industrial (Inmetro), em parceria com a Universidade Federal de Santa 
Catarina (UFSC), lançaram, em 2010, a Etiqueta Nacional de Conservação de Energia para residências e edifícios multifamiliares (Selo Procel Edifica) (BRASIL, 2012). Há ainda o Selo Casa Azul CAIXA, que objetiva classificar o desempenho socioambiental de projetos habitacionais financiados pela Caixa Econômica Federal, através de indicadores de sustentabilidade (JOHN; PRADO, 2010).

Vasconcelos e Vasconcelos (2008) advogam que a adoção do processo de etiquetagem no setor construtivo (em termos de certificação energética e de rótulos ecológicos) contribui, de maneira crescente, para uma melhor utilização das edificações e para uma maior conscientização sobre o conceito de sustentabilidade - visto que os selos "verdes" promovem, junto do consumidor, justamente os empreendimentos que apresentam melhores desempenhos ambientais. Entretanto, os autores chamam atenção para o fato de que, devido à proliferação de empreendimentos ditos "sustentáveis" (e que, muitas vezes, nem mesmo passam por um método consagrado de certificação), o usuário das edificações sente necessidade de entender o verdadeiro significado deste termo para melhor diferenciar as opções fornecidas pelo mercado imobiliário.

De forma semelhante, Zambrano (2008) percebe que, em função da complexidade dos problemas relacionados aos impactos negativos das edificações, as iniciativas de implementação de estratégias sustentáveis encontram-se em estágios iniciais, de maneira que não é possível observar resultados expressivos no sentido de afetar o perfil de desempenho do setor como um todo. Considerando essa situação, a autora chega à conclusão de que o mesmo carece de grandes esforços para acelerar o desenvolvimento de conhecimentos que possam gerar ações mais efetivas, tanto no âmbito do parque construído já existente, quanto das futuras edificações. Nesse sentido, é possível justificar a contribuição desta pesquisa, pois, através do mapeamento das estratégias de sustentabilidade nos empreendimentos residenciais das cidades estudadas e da posterior verificação de sua eficiência junto aos usuários, pretende-se produzir conhecimento que possa servir ao alcance de uma maior sustentabilidade do ambiente construído.

Zambrano (2008) considera ainda que a sustentabilidade do edifício começa a ser delineada no momento inicial de planejamento do empreendimento, dependendo de escolhas comprometidas ao longo de todo o processo evolutivo do projeto e estendendose até os procedimentos de uso e manutenção da obra edificada. Por isso, mecanismos de avaliação de desempenho de edificações, como avaliações de pós-ocupação (APO), são por ela recomendados, à medida que a etapa de uso pode confirmar e/ou potencializar um bom desempenho, assim como desperdiçar todo um esforço realizado nas etapas anteriores. Nos países desenvolvidos, a avaliação da qualidade de edifícios habitacionais já é um processo consolidado, sendo que tal avaliação deve perpassar por pelo menos três perspectivas: (i) dos ocupantes - e quão bem suas expectativas são atendidas; (ii) do desempenho ambiental, incluindo os recursos energia e água; e (iii) do seu desempenho econômico - valor de retorno do investimento (LEAMAN et al., 2010).

No caso específico da avaliação do desempenho ambiental das edificações, Silva (2007) explica que os métodos de avaliação atualmente disponíveis, de maneira geral, não abordam os aspectos sociais e econômicos da sustentabilidade, sendo direcionados para a verificação da eficiência energética e dos impactos ambientais gerados pelos edifícios. Nesse contexto, a autora avalia que relacionar medidas de desempenho das edificações a indicadores mais amplos de sustentabilidade representa um desafio. Assim, esta pesquisa também contribuiria com o debate sobre a problemática, ao identificar quais são as estratégias de sustentabilidade colocadas em prática nos edifícios analisados, bem como sua eficácia junto aos moradores. Para além das questões de eficiência, pretende-se identificar, assim, o papel dos moradores na redução de tais impactos, analisando-se seus 
hábitos e ações - ou seja, englobando também as dimensões sociais, culturais e econômicas do desenvolvimento sustentável.

Esta pesquisa, portanto, insere-se em uma linha de conduta - já observada em países desenvolvidos como Reino Unido, Holanda e EUA - que aponta para o enquadramento crescente das questões ambientais dentro do contexto mais amplo da sustentabilidade nas tradicionais avaliações; levantando a questão quanto ao fato das ferramentas existentes serem capazes (ou não) de facilmente se reconfigurarem para cumprirem essa nova agenda (COLE, 2005). Para tanto, é finalmente necessário distinguir entre os instrumentos de avaliação como "produto" e "processo". A noção de "produto" abrange todos os aspectos dos métodos de avaliação relacionados ao âmbito dos problemas de desempenho, incluindo o modo como estão estruturados, marcados e comunicados. Tais características técnicas são largamente estudadas pelos autores/pesquisadores da área em questão e, atualmente, representam o foco principal da discussão. "Processo", por outro lado, abrange uma série de questões relacionadas com a utilização, incluindo o desenvolvimento do próprio sistema de avaliação e, em particular, o papel da equipe de projeto e de outras partes interessadas como base para a tomada de decisões informadas. A distinção entre produto e processo permite sublinhar que o desenvolvimento de instrumentos de avaliação é apenas um meio para um fim e não um fim em si. Também permite evitar o enfoque excessivo e direcionado na melhoria constante e na comparação das características técnicas dos métodos, em vez de considerar as questões igualmente importantes do contexto em que operam, como eles estão sendo aplicados e

sua capacidade em responder a novas agendas. É sobre essa segunda linha de ação a pesquisa se aprofunda.

\section{MATERIAIS E MÉTODOS}

Conforme exposto, a presente comunicação objetiva apresentar resultados parciais, que enfocam a abordagem ambiental de uma pesquisa mais ampla, intitulada HABITAR VERTICAL: Avaliação da qualidade espacial e ambiental de edifícios de apartamentos. Os recortes da pesquisa foram: produção de edifícios de apartamentos destinados à classe média da sociedade e lançados pelo mercado imobiliário em cidades de médio porte brasileiras (Uberlândia - MG e Ribeirão Preto - SP). Enfocando as estratégias de conforto ambiental e de sustentabilidade presentes nos edifícios investigados, metodologicamente a pesquisa foi dividida em duas partes: (a) Identificação e análise de padrões projetuais em edifícios de apartamentos a partir de 2000 nas cidades estudadas (pesquisa bibliográfica e documental); e (b) Identificação dos modos de morar através da avaliação pós-ocupação funcional e ambiental aplicação dos estudos de casos nas cidades estudadas (pesquisa-ação).

$\mathrm{Na}$ primeira etapa da pesquisa (a), as seguintes etapas de trabalho e suas respectivas metodologias foram estabelecidas: (i) fundamentação teórica da pesquisa - em que foram analisados todos os selos de certificação utilizados no Brasil, suas especificidades e características; e (ii) mapeamento das estratégias de sustentabilidade colocadas em prática nos empreendimentos residenciais das cidades estudadas, por meio da elaboração de fichas de análise sobre os mesmos. Já a segunda etapa da pesquisa (b), que se encontra em desenvolvimento, estruturou-se da seguinte forma: (iii) revisão e ampliação dos métodos de APO inicialmente desenvolvidos em outras pesquisas para englobar questões relativas à qualidade ambiental e à sustentabilidade dos edifícios analisados; (iv) aplicação do método de APO em estudos de caso e (v) apresentação dos resultados a partir da tabulação dos dados obtidos pela aplicação de APO. As duas últimas etapas (iv e v) ainda não foram concluídas. 


\section{RESULTADOS E DISCUSSÃO}

\subsection{Mapeamento das estratégias de sustentabilidade}

A proposta inicial desta etapa da investigação era fazer uso dos empreendimentos já catalogados por uma pesquisa paralela, inserida no projeto HABITAR VERTICAL destinada à análise de funcionalidade dos edifícios ${ }^{1}$ - para então identificar as estratégias de sustentabilidade presentes nos mesmos. Entretanto, ao se iniciar a busca pelos dados necessários, constatou-se que os edifícios catalogados nas cidades de Uberlândia e Ribeirão Preto não apresentavam soluções sustentáveis na maioria dos casos. A título de ilustração, dos 63 empreendimentos catalogados em Uberlândia, apenas 2 deles contam com sistema de aquecimento solar, enquanto em outros 5 somente seu nome possui algum vínculo com o termo sustentabilidade - comprovando como esse conceito vendo sendo empregado enquanto estratégia de marketing.

A partir da constatação da ausência de estratégias de sustentabilidade nos edifícios de apartamentos das cidades elencadas, aumentou-se a abrangência de coleta de dados para o território nacional. Além disso, para melhor definir o recorte da investigação, resolveu-se fazer uma análise sobre a aplicação dessas estratégias em edifícios certificados com selos de ampla divulgação no Brasil. Assim, novos empreendimentos foram selecionados e as fichas foram feitas a partir dos mesmos. Foram identificados 36 edifícios de apartamentos certificados em todo o país e, mediante a disponibilidade de informações (presença de dados completos sobre todas as estratégias utilizadas em folhetos publicitários e/ou sites das construtoras, incorporadoras e escritórios de projeto responsáveis pelos mesmos), selecionaram-se 28 deles (ou seja, 78\% do total) para a produção das fichas de análise.

O mapeamento das estratégias de sustentabilidade foi realizado por meio do estudo dos seguintes processos de certificação: AQUA (versão brasileira do selo $\mathrm{HQE}$ e que aparece em $42 \%$ dos empreendimentos fichados), LEED (23\% dos edifícios), ProcelEdifica (19\% da amostra) e Casa Azul CAIXA (16\% das edificações). Como cada método de certificação apresenta pontuações diferentes, conforme o recurso ambiental analisado, buscou-se identificar, para orientar a criação das fichas, as principais estratégias de sustentabilidade indicadas nos mesmos - tanto as mais recorrentes, quanto aquelas com maior valor de pontuação para se obter a certificação ambiental.

As fichas de análise desenvolvidas, além de abranger imagens dos edifícios (perspectivas e plantas) e área para a anotação de eventuais observações, contêm os seguintes dados: (i) informações gerais sobre o empreendimento (tais como: ano, local, autor do projeto, número de blocos e de apartamentos); (ii) análise da configuração volumétrica e da forma plástica do edifício (tipo de planta e inserção urbana, por exemplo); (iii) aspectos técnicos (sistema construtivo e estrutural empregado); e, por fim, (iv) identificação das estratégias de sustentabilidade e de conforto ambiental adotadas (para a unidade residencial e para o empreendimento como um todo $)^{2}$. Assim, optou-se por identificar as práticas utilizadas em duas escalas: implantação e edifício - Figura 1; e apartamento - Figura 2, de maneira a se analisar inteiramente o objeto de estudo. As estratégias utilizadas nas fichas aqui usadas como exemplos (Figuras 1 e 2) foram assinaladas em laranja.

\footnotetext{
${ }^{1}$ Resultados sobre esta linha de investigação estão disponíveis na publicação: Avaliação da qualidade espacial de edifícios de apartamentos em cidades médias, apresentados neste mesmo evento.

${ }^{2}$ As imagens e demais dados sobre as edificações aqui ilustradas - Figuras 1 e 2 - foram omitidos, pois o objetivo deste artigo é apresentar os dados gerais da pesquisa e não análises de edifícios específicos.
} 
Figura 1 - Parte de uma ficha com as estratégias utilizadas no empreendimento
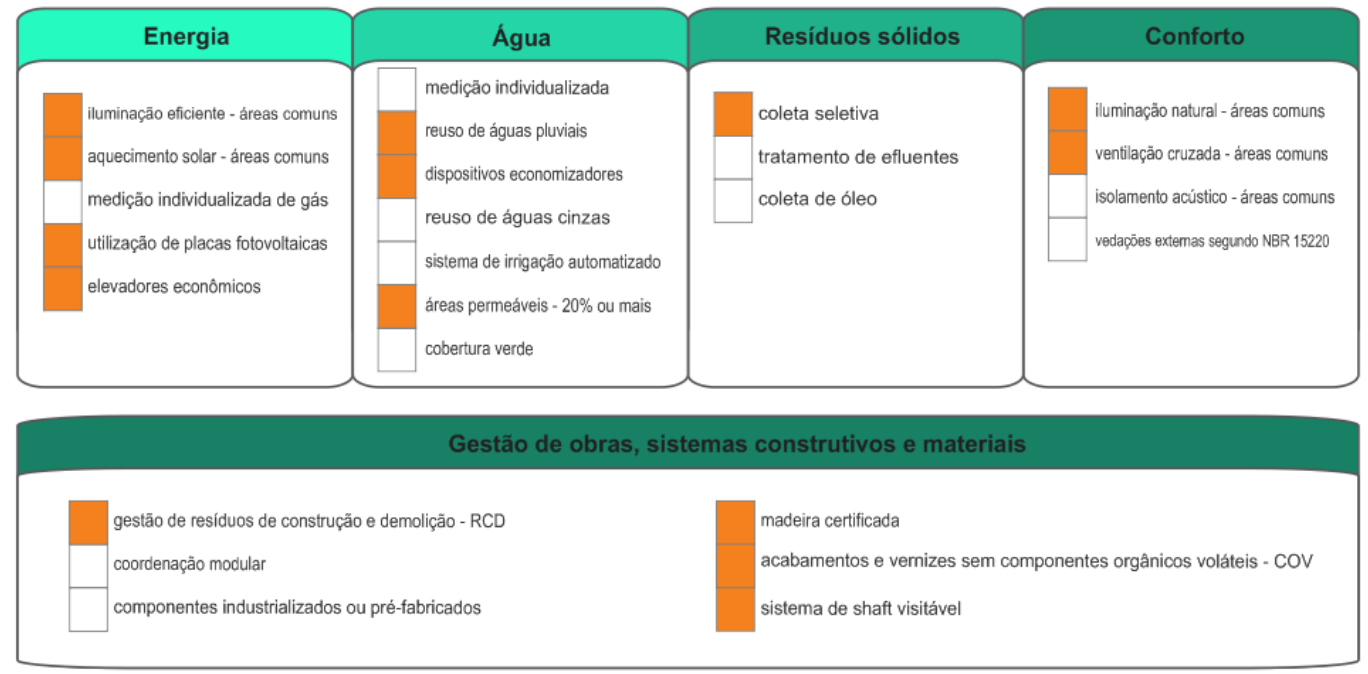

Fonte: Organizado pelos autores (2013).

Figura 2 - Parte de uma ficha com as estratégias utilizadas na unidade residencial

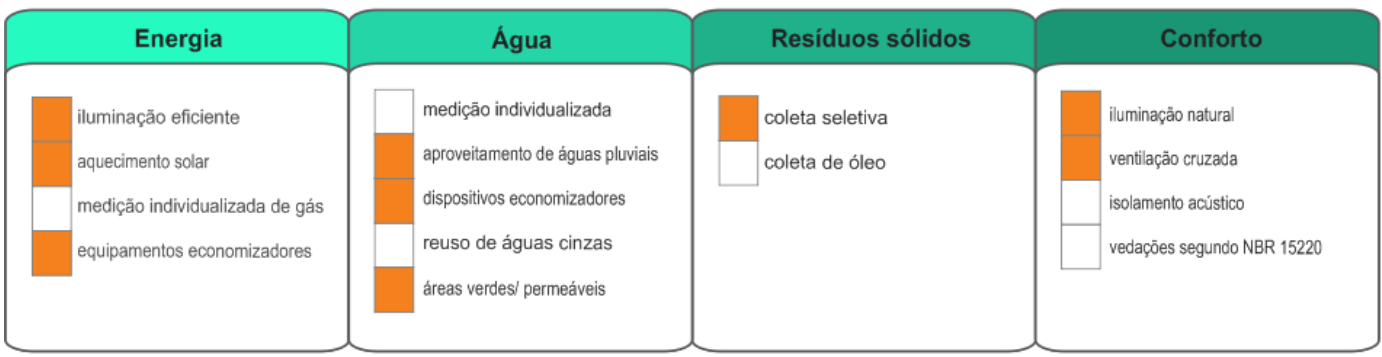

Fonte: Organizado pelos autores (2013).

Quanto às estratégias em si, conforme pode ser observado nas imagens acima, foram agrupadas conforme diferentes aspectos: energia, água, resíduos sólidos, conforto ambiental e gestão de obras, sistemas construtivos e materiais. A tabulação dos dados dessas fichas permite concluir que, mesmo nos edifícios certificados, a participação das estratégias ainda se faz de forma incipiente: analisando o recurso água (Figura 3), por exemplo, a principal estratégia utilizada é a adoção de $20 \%$ ou mais de áreas permeáveis (a qual aparece em 68\% dos empreendimentos), ao passo que somente $46 \%$ dos mesmos contam com sistemas de reuso de águas pluviais ou com equipamentos mais simples (como dispositivos economizadores, a exemplo das válvulas de descarga de duplo fluxo); $7 \%$ deles possuem sistema de reuso de águas cinzas e/ou de irrigação automatizado e nenhum edifício fichado possui cobertura verde.

As soluções ligadas à energia também ilustram essa situação: o emprego de sistema de aquecimento solar - tecnologia amplamente consolidada no cenário nacional - se faz presente em apenas 50\% dos empreendimentos. De forma semelhante, as estratégias relacionadas aos processos construtivos utilizados têm participação pouco expressiva: apenas $32 \%$ dos empreendimentos contam com gestão de resíduos de construção e demolição, enquanto somente $4 \%$ deles seguem princípios de coordenação modular. As únicas estratégias que aparecem em maior escala (acima de $60 \%$ nas áreas comuns dos empreendimentos e nos apartamentos) são: iluminação natural e ventilação cruzada isto é, aquelas relacionadas a princípios bioclimáticos de concepção projetual, que não necessariamente exigem o emprego de recursos tecnológicos mais sofisticados. Dessa 
forma, surge a hipótese de que, para se obter uma certificação de desempenho ambiental no Brasil, nem sempre é necessário adotar medidas sustentáveis em vários níveis.

Figura 3 - Estratégias de sustentabilidade relacionadas ao consumo de água

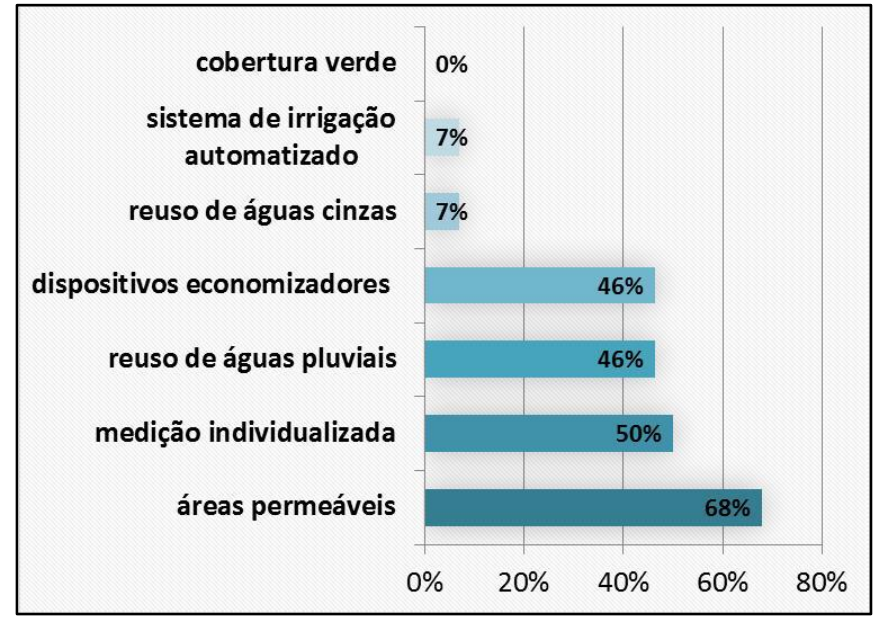

Fonte: Organizado pelos autores (2014).

\subsection{Revisão do método de APO}

Conforme exposto, a etapa seguinte da pesquisa previa a revisão dos métodos de APO para inserir questões sobre a qualidade ambiental dos empreendimentos. Essas questões se dividiram em três categorias (Quadro 1): a primeira é direcionada ao próprio pesquisador, responsável por aplicar os questionários e coletar informações acerca dos aspectos construtivos e dos sistemas envolvidos no edifício analisado; a segunda busca identificar a presença de estratégias na unidade residencial, compreendendo eventuais diferenças entre os apartamentos de um mesmo conjunto habitacional; já a terceira categoria é voltada aos moradores, tratando de ações, preferências e hábitos domiciliares, exemplificados aqui no Quadro 1 por seu comportamento com relação à economia de água ${ }^{3}$.

Sendo assim, entendemos que seja possível avaliar tanto a sustentabilidade dos empreendimentos em termos técnicos, quanto o grau de consciência ambiental dos seus usuários. Afinal, diferentes estudos demonstram que, embora alguns edifícios incorporem estratégias de sustentabilidade (a exemplo de mecanismos de aquecimento solar e reuso de água), caso o usuário não tenha consciência quanto à necessidade de reduzir os impactos sobre o meio ambiente, os níveis de consumo de água e energia continuam inadequados (ver especialmente VISSCHER et al., 2013).

O questionário inicial também foi revisto em relação à necessidade de alteração da linguagem técnica para incluir termos menos formais e mais acessíveis a leigos, facilitando sua participação e colaboração com o processo. Tal percepção partiu da aplicação dos métodos de APO em um edifício residencial de Uberlândia (MG), no início deste ano, com o intuito de testar o aplicativo para tablet - desenvolvido no mesmo núcleo de pesquisa, mas em outra linha de investigação (intitulada $A P O$ digital), que se baseava justamente em criá-lo para dinamizar o processo e facilitar a tabulação dos dados. Ressalta-se que as questões elaboradas foram então inseridas na ferramenta digital junto com as aquelas preexistentes (relativas à investigação sobre a funcionalidade dos apartamentos, os perfis familiares e modos de morar dos usuários).

\footnotetext{
${ }^{3}$ Todas as categorias abrangem aspectos relativos ao conforto ambiental e às ações de sustentabilidade presentes nos edifícios e/ou operacionalizadas pelos usuários. Especificamente quanto aos hábitos dos moradores, as questões foram agrupadas em: água, energia, resíduos, alimentos, vegetação e mobilidade urbana. Pretende-se, em outra publicação, explicar a metodologia utilizada de maneira mais aprofundada.
} 
O recurso desenvolvido, portanto, está sendo utilizado durante a aplicação de APO nos estudos de caso selecionados nas cidades de Ribeirão Preto e Uberlândia.

\section{Quadro 1 - Exemplos de questões sobre qualidade ambiental inseridas na APO}

\begin{tabular}{|c|l|}
\hline \multicolumn{1}{|c|}{ CATEGORIA } & \multicolumn{1}{c|}{ QUESTÃO } \\
\hline \multirow{4}{*}{ EDIFÍCIO } & Quais dispositivos economizadores de energia o edifício possui? \\
( ) Sistema de aquecimento solar \\
( ) Placas fotovoltaicas \\
( ) Elevadores econômicos \\
( ) Iluminação eficiente - áreas comuns \\
( ) Nenhum
\end{tabular}

Fonte: Organizado pelos autores (2014).

\section{CONCLUSÕES}

O contato com o material da pesquisa permitiu comprovar como o emprego de estratégias voltadas à melhoria da qualidade ambiental e à sustentabilidade do ambiente construído ainda é incipiente nos edifícios de apartamentos brasileiros - tanto naqueles edificados nas cidades médias, especialmente Uberlândia e Ribeirão Preto, por processos tradicionais; quanto nos empreendimentos que incorporaram a prática recente da certificação ambiental. Muitas vezes, conforme salientado, as soluções sustentáveis são adotadas como critério de valorização econômica dos empreendimentos pelas construtoras e imobiliárias, enquanto outras vezes estão presentes nos encartes publicitários em conceitos vagos, que pouco informam os compradores - isto é, enquanto estratégias mais relacionadas à divulgação dos imóveis que realmente com a redução dos impactos ambientais.

Nesse contexto, as fichas produzidas constituem recurso de grande interesse para futuras pesquisas que se proponham a compreender o estado da arte da sustentabilidade em habitações verticais do Brasil, ou que enfoquem os processos de certificação existentes, além de outras questões identificadas (como a própria tipologia e inserção urbana desses empreendimentos). Por outro lado, apesar de uma verificação mais ampla da hipótese da baixa qualidade ambiental dos edifícios ainda não ter sido realizada (a aplicação de APO nos estudos de caso ainda está em desenvolvimento), acredita-se que o esforço demandado para a preparação do material irá resultar em um processo de avaliação mais rico e coerente com os objetivos da pesquisa, bem como com a realidade dos usuários de tais edificações. Desse modo, espera-se que seja possível entender a atual situação de 
Uberlândia e Ribeirão Preto no que diz respeito, sobretudo, ao comportamento do usuário, identificando como os moradores atuam para reduzir os impactos do habitar.

\section{AGRADECIMENTOS}

Agradecemos aos órgãos financiadores da pesquisa: CNPq, FAPEMIG e PROGRAD/UFU.

\section{REFERÊNCIAS}

BRANDÃO, D. Q.; HEINECK, L. F. M. Significado multidimensional e dinâmico do morar: compreendendo as modificações na fase de uso e propondo flexibilidade nas habitações sociais. Ambiente Construído, v.3, n.4, p.35-48, out./dez. 2003.

BRASIL. MINISTÉRIO DO DESENVOLVIMENTO, INDÚSTRIA E COMÉRCIO EXTERIOR. INSTITUTO NACIONAL DE METROLOGIA, QUALIDADE E TECNOLOGIA. Portaria n. ${ }^{\circ}$ 18, de 16 de janeiro de 2012. Aprova a revisão do Regulamento Técnico da Qualidade - RTQ para o Nível de Eficiência Energética de Edificações Residenciais.

COLE, R. J. Building environmental assessment methods: redefining intentions and roles. Building Research \& Information, v.33, n.5, p.455-467, 2005.

CORDEIRO FILHO, A. Empreendedorismo no mercado imobiliário habitacional. São Paulo: Atlas, 2008.

EDWARDS, B.; HYETT, P. Guía básica de la sostenibilidad. Barcelona: Gustavo Gilli, 2005.

JOHN, V. M.; PRADO, R. T. (coord) Boas práticas para habitação mais sustentável. São Paulo: Páginas \& Letras, 2010.

LAMBERTS, R.; DUTRA, L.; RUTTKAY, P. Eficiência energética na arquitetura. São Paulo: PW, 1997.

LEAMAN, A.; STEVENSON, F.; BORDASS, B. Building evaluation: practice and principles. Building Research \& Information, v.38, n.5, p.564-577, 2010.

PALERMO, C. Sustentabilidade Social do Habitar. Florianópolis: Edição da autora, 2009.

SILVA, V. G. Indicadores de sustentabilidade de edifícios: estado da arte e desafios para desenvolvimento no Brasil. Ambiente Construído, Porto Alegre, v.7, n.1, p.47-66, jan./mar. 2007.

VASCONCELOS, D. L. B.; VASCONCELOS, R. L. Sustentabilidade: ferramenta de marketing ou instrumento essencial. In: VII Seminário Internacional da LARES, 2008, São Paulo. Disponível em: <http://www.lares.org.br/2008/img/Artigo022-BatalhaVasconcelos_Rev_2.pdf>. Acesso em: 20 nov. 2012.

VILLA, S. B. Morar em Apartamentos: a produção dos espaços privados e semi-privados nos apartamentos ofertados pelo mercado imobiliário no século XXI - São Paulo e Ribeirão Preto. Critérios para Avaliação Pós-Ocupação. 2008. Tese (Doutorado) Universidade de São Paulo, São Paulo, 2008.

VILLA, S. B. A APO como elemento norteador de práticas de projeto de HIS: O caso do projeto [MORA]. In: CONGRESSO INTERNACIONAL HABITAÇÃO NO ESPAÇO LUSÓFONO, Anais..., Lisboa, Portugal, 22-24 Setembro 2010.

VISSCHER, H.; WERF, E. V.; VOORDT, T. J. M. V. Eficiência energética no parque habitacional holandês. 2013. In: VILLA, S. B.; ORNSTEIN, S. W. (Org.) Qualidade ambiental na habitação. São Paulo: Oficina de Textos, 2013. p.343-358.

ZAMBRANO, L. M. A. Integração dos princípios de sustentabilidade ao projeto de arquitetura. 2008. Tese (Doutorado em Ciências em Arquitetura) - Universidade Federal do Rio de Janeiro, Rio de Janeiro, 2008. 